\title{
Effect of clomiphene citrate on uterine hemodynamics in women with unexplained infertility
}

This article was published in the following Dove Press journal: International Journal of Women's Health

\section{Eman Omran \\ Mohamed El-Sharkawy \\ Akmal El-Mazny \\ Mohamed Hammam \\ Wafaa Ramadan \\ Dina Latif \\ Dalia Samir \\ Sherine Sobh}

Department of Obstetrics and Gynecology, Kasr Al-Ainy Hospital, Cairo University, Cairo, Egypt
Correspondence: Eman Omran Department of Obstetrics and Gynecology, Faculty of Medicine, Al-Saray St, Al-Manial I 1956, Cairo, Egypt

$\mathrm{Tel}+20223682030$

Fax +20223682030

Email omraneman9@gmail.com
Purpose: The aim of the study was to evaluate the effect of clomiphene citrate on uterine artery blood flow using pulsed Doppler and endometrial and subendometrial micro vascularization using 3D power Doppler in unexplained infertility.

Patients and methods: In a prospective observational study at a university teaching hospital, the mid-luteal (peri-implantation) endometrial thickness and volume, uterine artery pulsatility index (PI) and resistance index (RI), endometrial and subendometrial vascularization index (VI), flow index (FI), and vascularization flow index (VFI), and serum estradiol and progesterone levels were compared between natural and clomiphene citrate stimulated cycles in the same group of 50 patients with unexplained infertility. Statistical analysis was done using paired $t$-test to compare different study variables.

Results: The primary outcome, which was the endometrial flow index, was significantly lower in the stimulated cycles (mean \pm SD: $23.89 \pm 7.96$ vs $27.49 \pm 8.73$, mean difference (95\% CI): $-3.6(-2,-5.9) ; P=0.03)$. The mean $\pm \mathrm{SD}$ of endometrial thickness $(10.92 \pm 3.04$ vs $12.46 \pm 3.08 \mathrm{~mm} ; P=0.01)$, volume $\left(4.57 \pm 1.28\right.$ vs $\left.5.26 \pm 1.32 \mathrm{~cm}^{3} ; P=0.009\right)$, endometrial VI $(0.86 \pm 0.15$ vs $0.95 \% \pm 0.21 \% ; P=0.02)$, VFI $(0.25 \pm 0.08$ vs $0.31 \pm 0.12 ; P=0.004)$, subendometrial VI ( $1.93 \pm 0.68$ vs $2.26 \% \pm 0.75 \% ; P=0.02)$, FI ( $26.81 \pm 9.16$ vs $30.73 \pm 9.87 ; P=0.04)$, and VFI $(0.68 \pm 0.18$ vs $0.79 \pm 0.21 ; P=0.006)$ were significantly lower in the stimulated cycles. However, there were no significant differences in the uterine artery PI $(P=0.12)$ and RI $(P=0.08)$ or serum estradiol $(P=0.54)$ and progesterone $(P=0.37)$ levels between natural and stimulated cycles.

Conclusion: Peri-implantation endometrial perfusion is significantly lower in clomiphene citrate stimulated cycles when compared to natural ones in patients with unexplained infertility.

Keywords: subendometrial blood flow, 3D power Doppler, endometrial blood flow, uterine artery Doppler

\section{Introduction}

Unexplained infertility still constitutes a considerable percentage of infertility (up to $30 \%) .{ }^{1}$ It is usually a diagnosis made in couples in whom the standard investigations provide adequate sperm production, evidence of ovulation, and patency of Fallopian tubes after 12 months of attempting conception or after 6 months in women

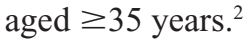

Blood flow to the uterus changes cyclically. ${ }^{3}$ It has been considered that good blood supply to the endometrium is an essential requirement for normal implantation. ${ }^{4}$ Therefore, there has been increasing interest in assessment of this perfusion as a method of prediction of endometrial receptivity. Some studies correlated lower 
uterine blood flow indices to fertility outcome in IVF (in vitro fertilization) cycles, ${ }^{5-8}$ and intrauterine insemination cycles. $^{9}$

Goswamy et $\mathrm{al}^{10}$ first suggested that decreased uterine blood flow may be a cause of infertility. Thereafter, some studies suggested affection of uterine blood flow in unexplained infertile cases. . $^{3,4,11,12}$

Clomiphene citrate remains a first-line therapy for ovulation induction. ${ }^{13}$ It can be used in unexplained infertile cases for ovarian stimulation, especially in combination with intrauterine insemination cycles. ${ }^{13}$

Although clomiphene citrate has been the most prescribed of all the fertility medications available today, few studies have assessed the uterine blood flow indices during ovarian stimulation by clomiphene citrate. ${ }^{14,15}$ Consequently, little is known of the effect of ovarian stimulation on this flow, especially in unexplained infertility.

Therefore, the aim of the present study was to evaluate the effect of clomiphene citrate on uterine artery blood flow, using a pulsed Doppler, and endometrial and subendometrial microvascularization, using a 3D power Doppler, in patients with unexplained infertility.

\section{Patients and methods}

This prospective observational study, which had a crossover design, was conducted at the Department of Obstetrics and Gynecology, Faculty of Medicine, Cairo University, during the period from October 2014 to October 2016. The study was approved by the Research Ethics Committee (Department of Obstetrics and Gynecology Ethics Committee), and written informed consent was obtained from all participants. Reporting of the present study followed the Strobe checklist. ${ }^{16}$ The ethical standards of the Declaration of Helsinki were followed, and the study was registered in ClinicalTrial.gov registry as an observational study (NCT03322852).

The study population included 50 patients with primary or secondary unexplained infertility for more than 2 years. The diagnosis of unexplained infertility was based on normal semen analysis, documentation of ovulation by transvaginal ultrasonography and normal mid-luteal serum progesterone levels, and documentation of normal uterine cavity and bilateral tubal patency via hysterosalpingography and/or hysterolaparoscopy (if indicated). ${ }^{2}$ The sampling was done consecutively. That means we recruited eligible participants consecutively until the study target number was achieved.

Inclusion criteria were age 25-35 years, body mass index $(\mathrm{BMI})<30 \mathrm{~kg} / \mathrm{m}^{2}$, regular menstruation, and normal pelvic examination and ultrasonography. Exclusion criteria were history of pelvic operations, including cesarean section; history of pelvic inflammatory disease; clinical features suggestive of endometriosis; any pelvic pathology, including uterine fibroids and ovarian cysts; any general disease or medication that could potentially affect pelvic blood flow, and smoking.

Transvaginal ultrasound (Voluson 730; Kretz, Zipf, Austria) examinations were done by the same researcher (AEM) (to decrease bias due to interobserver variability) during the mid-luteal (peri-implantation) phase (days 20-22) of the menstrual cycle. At the same visit, blood samples were collected and immediately centrifuged; the sera were separated and stored at $-70^{\circ} \mathrm{C}$ until subsequent analysis. Serum progesterone and estradiol levels were measured using electrochemiluminescence immunoassay.

Using two-dimensional ultrasound, the endometrial thickness was measured as the thickest part (double layer) in the sagittal plane, as shown in Figure 1. Then, the flow velocity waveforms were obtained from the ascending branch of the uterine artery on both sides of the internal cervical opening (Figure 2). Three similar consecutive waveforms of good quality were included. The right and left uterine artery pulsatility index (PI) and resistance index (RI) were calculated, and the averaged PI and RI were given.

The ultrasound was then switched to the $3 \mathrm{D}$ power Doppler mode. The setting conditions for this study were standardized using a frequency at 3-9 $\mathrm{MHz}$, a pulse repetition frequency at $0.6 \mathrm{kHz}$, a gain at -4.0 , and a wall motion filter at low 1. The Virtual Organ Computer-Aided Analysis (VOCAL) Imaging Program was used to calculate the endometrial volume and 3D power Doppler indices within the endometrium and the subendometrial region (Figure 3) through the application of "shell-imaging" within $1 \mathrm{~mm}$

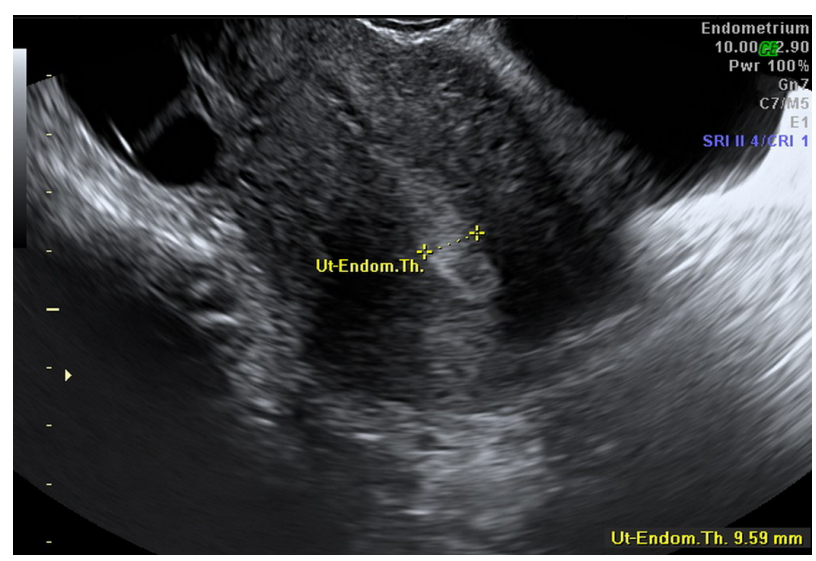

Figure I Two-dimensional ultrasound measurement of endometrial thickness. Abbreviation: Ut-Endom.Th., ultrasound measurement of endometrial thickness. 


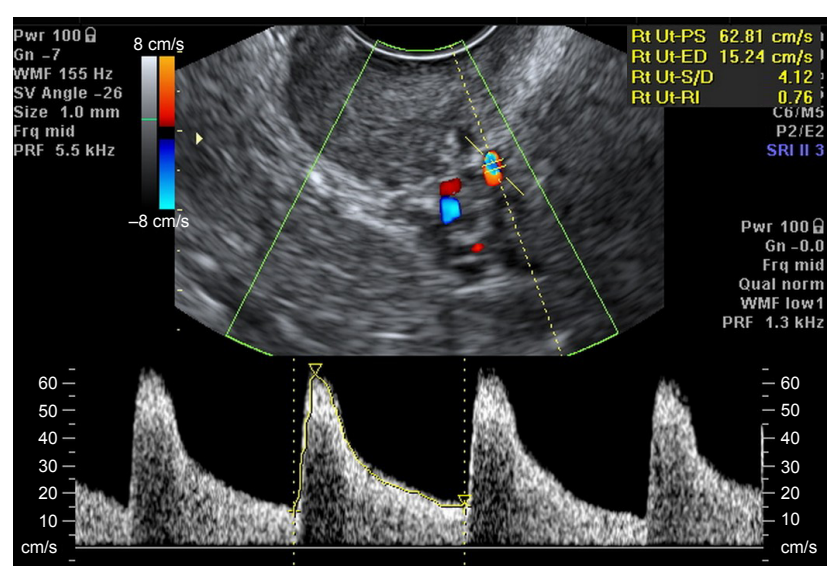

Figure 2 Two-dimensional color Doppler of uterine artery flow velocity waveforms.

parallel to the originally defined myometrial-endometrial contour. A subendometrial shell within $1 \mathrm{~mm}$ was chosen (not 5 or $10 \mathrm{~mm}$ ) as this is the area that undergoes cyclic changes. ${ }^{17}$

The vascularization index (VI) calculates the ratio of the number of color voxels to the total number of voxels (\%) and represents the presence of blood vessels (vascularity). Flow index (FI) calculates the mean power Doppler signal intensity (0-100) and represents the average intensity of blood flow. Vascularization flow index (VFI) is calculated by multiplying VI and FI (0-100), and represents a combination of vascularity and flow intensity. ${ }^{18} 3 \mathrm{D}$ power Doppler indices were prefered to 2D Doppler measurment of endometrial and subendometrial arteries, as they gave more accurate information about endometrial and subendometrial vascularity. ${ }^{4}$

In the following cycle, all patients had mild ovarian stimulation; clomiphene citrate (Clomid; Aventis Pharma, Cairo, Egypt) was given $100 \mathrm{mg} /$ day orally starting from

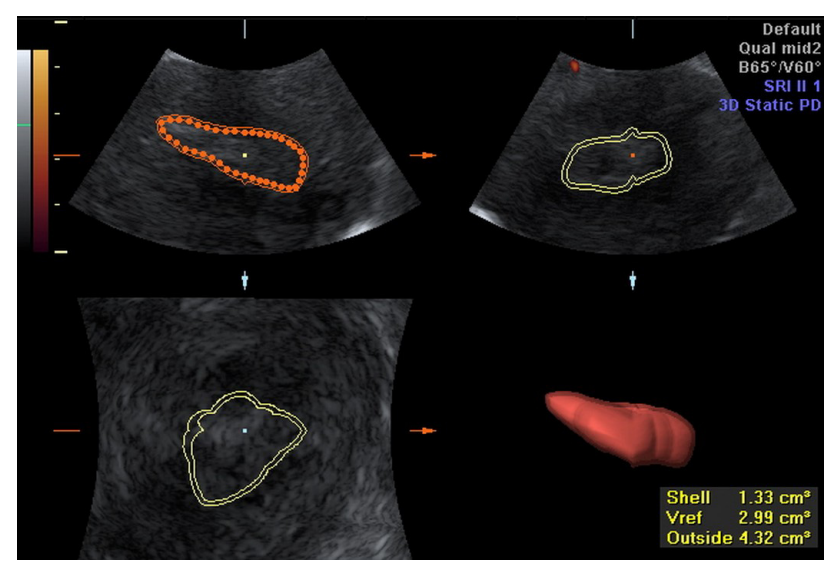

Figure 3 VOCAL of the subendometrial "shell". Abbreviation: VOCAL, Virtual Organ Computer-Aided Analysis. the 3rd day of the cycle for 5 days. During days 20-22 of the cycle, the previous protocol was repeated, and the ultrasonographic, Doppler, and hormonal parameters were compared between spontaneous and stimulated cycles in the same group of patients.

The study primary outcome was endometrial FI in stimulated versus natural cycles. Secondary outcomes were other Doppler flow indices of uterine arteries, endometrial region, and subendometrial region.

Sample size was calculated according to the endometrial flow index as the study primary outcome. According to a previous study, the mid-luteal FI in natural cycles in cases with unexplained infertility was 25 , and the standard deviation (SD) was 5.8. ${ }^{3}$ Setting the power at $80 \%$, the alpha error at 0.05 , and the minimal clinically significant difference of FI at 2, and using the paired $t$-test, we needed 50 patients in the present study. Sample size calculation was done by IBM SPSS SamplePower software, release 3.0.1 (IBM Corp., Armonk, NY, USA).

Data were expressed as mean \pm SD or number (\%). The paired Student's $t$-test was used to compare relevant variables between stimulated and natural cycles. Hypothesis testing was done 2-tailed, and 95\% confidence intervals were provided for tests' statistics. A $P$-value $<0.05$ was considered statistically significant. Statistical analysis was done using SPSS software, version 23 (IBM Corp.).

\section{Results}

A flowchart of the study population is illustrated in Figure 4. Seventy-four cases who met the inclusion criteria having unexplained infertility were screened for eligibility, and 24 were excluded due to exclusion criteria $(n=22)$ or refusal to participate in the study $(\mathrm{n}=2)$.

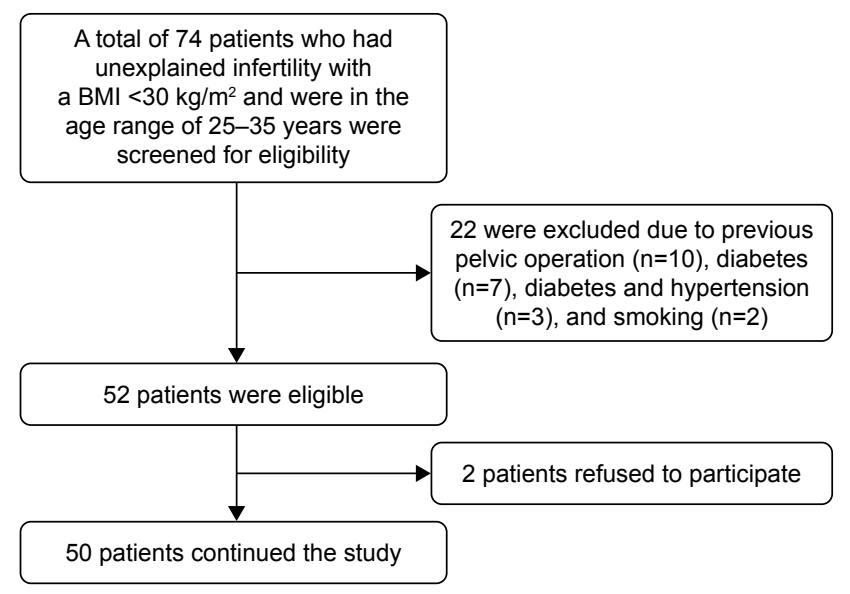

Figure 4 Flowchart of the study population. Abbreviation: BMI, body mass index. 
Table I Patients' characteristics

\begin{tabular}{ll}
\hline Characteristic & Value \\
\hline Number of patients & 50 \\
Primary infertility & $27(54)$ \\
Secondary infertility & $23(46)$ \\
Duration of infertility (years) & $3.91 \pm 1.12$ \\
Age (years) & $29.76 \pm 2.19$ \\
Parity (number of previous deliveries) & $0.95 \pm 0.83$ \\
Menstrual cycle (days) & $28.12 \pm 2.45$ \\
Body mass index $\left(\mathrm{kg} / \mathrm{m}^{2}\right)$ & $24.04 \pm 2.16$ \\
\hline
\end{tabular}

Note: Values are given as $\mathrm{n}(\%)$ or mean $\pm \mathrm{SD}$.

Abbreviation: SD, standard deviation.

The study population consisted of 50 patients with primary $(n=27 ; 54 \%)$ or secondary $(n=23 ; 46 \%)$ unexplained infertility for more than 2 years $(3.91 \pm 1.12)$. The age, parity, duration of menstrual cycle, and BMI are shown in Table 1.

The primary outcome, which was the endometrial flow index, was significantly lower in the stimulated cycles (mean \pm SD: $23.89 \pm 7.96$ vs $27.49 \pm 8.73$, mean difference (95\% CI): $-3.6(-2,-5.9) ; P=0.03)$ (Table 2).

The mean $\pm \mathrm{SD}$ values of endometrial thickness (10.92 \pm 3.04 vs $12.46 \pm 3.08 \mathrm{~mm} ; P=0.01)$, volume $(4.57 \pm 1.28$ vs $\left.5.26 \pm 1.32 \mathrm{~cm}^{3} ; P=0.009\right)$, endometrial VI $(0.86 \pm 0.15$ vs $0.95 \% \pm 0.21 \% ; P=0.02)$, and VFI $(0.25 \pm 0.08$ vs $0.31 \pm 0.12$; $P=0.004)$, subendometrial VI ( $1.93 \pm 0.68$ vs $2.26 \% \pm 0.75 \%$; $P=0.02)$, FI (26.81 \pm 9.16 vs $30.73 \pm 9.87 ; P=0.04)$, and VFI $(0.68 \pm 0.18$ vs $0.79 \pm 0.21 ; P=0.006)$ were significantly lower in the stimulated cycles (Table 2).

However, there were no significant differences in the uterine artery $\mathrm{PI}(P=0.12)$ and $\mathrm{RI}(P=0.08)$ or serum estradiol
( $P=0.54)$ and progesterone $(P=0.37)$ levels between natural and stimulated cycles (Table 2).

\section{Discussion}

In the present study, we found significantly lower 3D power Doppler flow indices of endometrial and subendometrial regions in stimulated cycles by clomiphene citrate in comparison with natural ones in the same patients who had unexplained infertility. The endometrial thickness $(P=0.01)$, volume $(P=0.009)$, endometrial VI $(P=0.02)$, FI $(P=0.03)$, VFI $(P=0.004)$, subendometrial VI $(P=0.02)$, FI $(P=0.04)$, and VFI $(P=0.006)$ were significantly lower in the stimulated cycle than in the natural cycle.

Raine-Fenning et $\mathrm{al}^{3}$ did a serial 3D power Doppler scan on the endometrial and subendometrial regions to patients with unexplained infertility and compared their findings to the control fertile group. Interestingly, they found cyclic endometrial perfusion changes with an increase in periovulatory followed by a decrease in the early luteal phase. Then another increase in Doppler indices occurred until the next cycle. These cyclic changes were present in both study groups. However, they were significantly lower in the unexplained infertility group. ${ }^{3}$ Also, El-Mazny et $\mathrm{al}^{11}$ used a $3 \mathrm{D}$ power Doppler to evaluate endometrial and subendometrial microvascularization in women with unexplained infertility. They reported that peri-implantation endometrial perfusion is impaired in women with unexplained infertility compared with that in the fertile control group, irrespective of the endometrial measurements and hormonal levels. ${ }^{11}$ In addition, Zebitay et al ${ }^{12}$ recently found lower 2D Doppler parameters of the endometrium in unexplained infertile patients in comparison

Table 2 Comparison of ultrasonography, Doppler, and hormonal parameters between stimulated and natural cycles

\begin{tabular}{|c|c|c|c|c|}
\hline Variable & Stimulated cycles & Natural cycles & $\begin{array}{l}\text { Difference between stimulated } \\
\text { and spontaneous cycles }(95 \% \mathrm{Cl})\end{array}$ & $P$-value \\
\hline Endometrial thickness $(\mathrm{mm})^{*}$ & $10.92 \pm 3.04(10.06,11.78)$ & $12.46 \pm 3.08(\mid 1.58,13.34)$ & $-1.54(-0.67,-2.40)$ & 0.01 \\
\hline Endometrial volume $\left(\mathrm{cm}^{3}\right)^{*}$ & $4.57 \pm 1.28(4.21,4.93)$ & $5.26 \pm 1.32(4.88,5.64)$ & $-0.69(0.32,1.10)$ & 0.009 \\
\hline Uterine artery PI & $2.07 \pm 0.59(1.90,2.24)$ & $1.89 \pm 0.54(1.74,2.04)$ & $0.18(-0.02,0.33)$ & 0.12 \\
\hline Uterine artery RI & $0.84 \pm 0.19(0.79,0.89)$ & $0.78 \pm 0.15(0.74,0.82)$ & $0.06(-0.01,0.10)$ & 0.08 \\
\hline Endometrial VI (\%)* & $0.86 \pm 0.15(0.82,0.90)$ & $0.95 \pm 0.21(0.89,1.01)$ & $-0.09(-0.04,-0.14)$ & 0.02 \\
\hline Endometrial FI $(0-100)^{*}$ & $23.89 \pm 7.96(21.63,26.15)$ & $27.49 \pm 8.73(25.01,29.97)$ & $-3.60(-2.00,-5.90)$ & 0.03 \\
\hline Endometrial VFI $(0-100)^{*}$ & $0.25 \pm 0.08(0.23,0.27)$ & $0.31 \pm 0.12(0.28,0.34)$ & $-0.06(-0.03,-0.09)$ & 0.004 \\
\hline Subendometrial VI (\%)* & $1.93 \pm 0.68(1.74,2.12)$ & $2.26 \pm 0.75(2.05,2.47)$ & $-0.30(-0.13,-0.53)$ & 0.02 \\
\hline Subendometrial FI $(0-100)^{*}$ & $26.8 I \pm 9.16(24.2 I, 29.4 I)$ & $30.73 \pm 9.87(27.92,33.54)$ & $-3.90(-1.20,-6.60)$ & 0.04 \\
\hline Subendometrial VFI $(0-100)^{*}$ & $0.68 \pm 0.18(0.63,0.73)$ & $0.79 \pm 0.21(0.73,0.85)$ & $-0.11(-0.05,-0.17)$ & 0.006 \\
\hline Estradiol $(\mathrm{pg} / \mathrm{mL})$ & $87.65 \pm 23.76(80.90,94.40)$ & $84.79 \pm 22.84(78.30,91.28)$ & $2.90(-3.80,9.50)$ & 0.54 \\
\hline Progesterone (ng/mL) & $20.87 \pm 7.18(|8.83,22.9|)$ & $19.65 \pm 6.32(17.85,21.45)$ & $1.20(-0.70,3.20)$ & 0.37 \\
\hline
\end{tabular}

Notes: Values are given as mean \pm SD $(95 \% \mathrm{Cl})$ or mean difference $(95 \% \mathrm{Cl})$. *Statistically significant.

Abbreviations: PI, pulsatility index; RI, resistance index; VI, vascularization index; FI, flow index; VFI, vascularization flow index. 
with patients having other causes of infertility and healthy controls. However, power Doppler, in combination with 3D ultrasound, provides a unique tool to examine microvascularization and has been suggested to be better than 2D Doppler velocimetry in assessment of endometrial and subendometrial blood flow. ${ }^{4}$

Few studies compared endometrial blood flow between natural and stimulated cycles. Kupesic and Kurjak ${ }^{14}$ performed 2D Doppler velocimetry for the endometrial spiral arteries in healthy women attending an infertility clinic because of male factor infertility. They found lower spiral artery PI in natural cycles when compared with stimulated ones (1.13 vs 2.32 , respectively). ${ }^{14}$ However, they performed their study in the periovulatory and did not address the blood flow in the peri-implantation mid-luteal phase. $\mathrm{Ng}$ et al ${ }^{19}$ compared 3D power Doppler indices of endometrial and subendometrial regions in stimulated cycles for IVF and subsequent natural cycles (frozen embryo transfer cycle) in the same patients. They found periovulatory lower Doppler indices in stimulated cycles. Nevertheless, they did not assess the peri-implantation mid-luteal period.

The lower blood flow parameters in the endometrial and subendometrial regions in stimulated cycles can be due to the anti-estrogenic effect of clomiphene citrate. ${ }^{20,21}$ In addition, some studies have suggested that the number of estrogen and progesterone receptors is lower in the endometrium of stimulated cycles when compared to that of natural ones. ${ }^{22,23}$ Furthermore, Raine-Fenning et $\mathrm{al}^{3}$ have suggested endometrial aberrant local dynamic vascular changes such as vasoconstriction or decreased vasodilation in spontaneous cycles of women suffering from unexplained infertility. This hypothetical abnormal vascular response might get worse in stimulation cycles.

Our results also showed that there were no significant differences in the uterine artery PI $(P=0.12)$ and $\mathrm{RI}(P=0.08)$ between natural and stimulated cycles. This finding may be attributed to the presence of collateral circulation through the ovarian vessels. Therefore, uterine artery Doppler velocimetry may not reflect properly the actual endometrial and subendometrial blood flow. This explanation is supported by a study that found no correlation between 2D Doppler velocimetry of uterine artery and VI, FI, and VFI of the endometrial and subendometrial regions. ${ }^{24}$ In addition, this was in agreement with Nakai et al, ${ }^{15}$ who found that the uterine arterial blood flow was not significantly different between spontaneous and clomiphene citrate-stimulated cycles of women with unexplained infertility in the mid-luteal phase of the cycle.
The negative impact of clomiphene citrate on endometrial receptivity was recently suggested by Nakagawa et al, ${ }^{25}$ who reported lowered pregnancy rates in frozen-thawed IVF cycles up to 90 days after stimulation by clomiphene citrate.

Although some previous studies have shown that periovulatory decreased uterine blood flow in stimulated cycles by clomiphene citrate; these studies were mostly performed by $2 \mathrm{D}$ assessment, as were the studies done by Hsu et $\mathrm{al}^{26}$ and Kupesic and Kurjak. ${ }^{14}$

To the best of our knowledge, this is the first study that compared the 3D power Doppler endometrial and subendometrial blood flow parameters between the stimulated and natural cycles in the same women who had unexplained infertility. The choice of prospective crossover design eliminated the problem of confounding and validated our results.

However, the present study has limitations. There were no follow-up data about later fertility outcomes in relation to the decrease in the endometrial blood flow. However, the presented results highlighted the probability of affection of endometrial receptivity by clomiphene citrate. This needs future studies with a focus on correlation between changes in endometrial perfusion during stimulation to pregnancy outcome. Furthermore, correlation between our results and the exact local vascular changes needs further research aiming at discovering the histological and molecular changes in stimulated and natural cycles.

\section{Conclusion}

Based on our results, we conclude that peri-implantation endometrial perfusion is significantly lower in clomiphene citrate-stimulated cycles when compared to natural ones in patients with unexplained infertility. Our results need to be correlated to pregnancy outcome in future studies. In addition, since Letrozole has been known to have a lower impact on the endometrium when compared to clomiphene citrate, it would be of value to compare both drugs on uterine hemodynamics in future studies.

\section{Disclosure}

The authors report no conflicts of interest in this work.

\section{References}

1. Ray A, Shah A, Gudi A, Homburg R. Unexplained infertility: an update and review of practice. Reprod Biomed Online. 2012;24(6):591-602.

2. Practice Committee of American Society for Reproductive Medicine. Diagnostic evaluation of the infertile female: a committee opinion. Fertil Steril. 2012;98(2):302-307.

3. Raine-Fenning NJ, Campbell BK, Kendall NR, Clewes JS, Johnson IR. Endometrial and subendometrial perfusion are impaired in women with unexplained subfertility. Hum Reprod. 2004;19(11):2605-2614. 
4. Ng EH, Chan CC, Tang OS, Yeung WS, Ho PC. The role of endometrial blood flow measured by three-dimensional power Doppler ultrasound in the prediction of pregnancy during in vitro fertilization treatment. Eur J Obstet Gynecol Reprod Biol. 2007;135(1):8-16.

5. Mercé LT, Barco MJ, Bau S, Troyano J. Are endometrial parameters by three-dimensional ultrasound and power Doppler angiography related to in vitro fertilization/embryo transfer outcome? Fertil Steril. 2008;89(1):111-117.

6. Salle B, Bied-Damon V, Benchaib M, Desperes S, Gaucherand P, Rudigoz RC. Preliminary report of an ultrasonography and colour Doppler uterine score to predict uterine receptivity in an in-vitro fertilization programme. Hum Reprod. 1998;13(6):1669-1673.

7. Schild RL, Holthaus S, d'Alquen J, et al. Quantitative assessment of subendometrial blood flow by three-dimensional-ultrasound is an important predictive factor of implantation in an in-vitro fertilization programme. Hum Reprod. 2000;15(1):89-94.

8. Wang L, Qiao J, Li R, Zhen X, Liu Z. Role of endometrial blood flow assessment with color Doppler energy in predicting pregnancy outcome of IVF-ET cycles. Reprod Biol Endocrinol. 2010;8:122.

9. Engels V, Sanfrutos L, Pérez-Medina T, et al. Evaluation of endometrial and subendometrial vascularization and endometrial volume by 3-D power Doppler ultrasound and its relationship with age and pregnancy in intrauterine insemination cycles. Gynecol Obstet Invest. 2011;72(2):117-122.

10. Goswamy RK, Williams G, Steptoe PC. Decreased uterine perfusion - a cause of infertility. Hum Reprod. 1988;3(8):955-959.

11. El-Mazny A, Abou-Salem N, Elshenoufy H. Doppler study of uterine hemodynamics in women with unexplained infertility. Eur J Obstet Gynecol Reprod Biol. 2013;171(1):84-87.

12. Zebitay AG, Tutumlu M, Verit FF, et al. A comparative analysis of arterial blood flow in unexplained infertility, tubal infertility and fertile groups. Gynecol Endocrinol. 2016;32(6):442-445.

13. Practice Committee of the American Society for Reproductive Medicine. Use of clomiphene citrate in infertile women: a committee opinion. Fertil Steril. 2013;100(2):341-348.

14. Kupesic S, Kurjak A. Uterine and ovarian perfusion during the periovulatory period assessed by transvaginal color Doppler. Fertil Steril. 1993;60(3):439-443.

15. Nakai A, Yokota A, Koshino T, Araki T. Assessment of endometrial perfusion with Doppler ultrasound in spontaneous and stimulated menstrual cycles. J Nippon Med Sch. 2002;69(4):328-332.
16. STROBE statement-checklist of items that should be included in reports of observational studies (STROBE initiative). Int J Public Health. 2008; 53(1):3-4.

17. Noe M, Kunz G, Herbertz M, Mall G, Leyendecker G. The cyclic pattern of the immunocytochemical expression of oestrogen and progesterone receptors in human myometrial and endometrial layers: characterization of the endometrial-subendometrial unit. Hum Reprod. 1999; 14(1):190-197.

18. Pairleitner H, Steiner H, Hasenoehrl G, Staudach A. Three-dimensional power Doppler sonography: imaging and quantifying blood flow and vascularization. Ultrasound Obstet Gynecol. 1999;14(2):139-143.

19. Ng EH, Chan CC, Tang OS, Yeung WS, Ho PC. Comparison of endometrial and subendometrial blood flow measured by three-dimensional power Doppler ultrasound between stimulated and natural cycles in the same patients. Hum Reprod. 2004;19(10):2385-2390.

20. Nakamura Y, Ono M, Yoshida Y, Sugino N, Ueda K, Kato H. Effects of clomiphene citrate on the endometrial thickness and echogenic pattern of the endometrium. Fertil Steril. 1997;67(2):256-260.

21. Massai MR, de Ziegler D, Lesobre V, Bergeron C, Frydman R, Bouchard P. Clomiphene citrate affects cervical mucus and endometrial morphology independently of the changes in plasma hormonal levels induced by multiple follicular recruitment. Fertil Steril. 1993;59(6):1179-1186.

22. Bourgain C, Ubaldi F, Tavaniotou A, Smitz J, Van Steirteghem AC, Devroey P. Endometrial hormone receptors and proliferation index in the periovulatory phase of stimulated embryo transfer cycles in comparison with natural cycles and relation to clinical pregnancy outcome. Fertil Steril. 2002;78(2):237-244.

23. Hadi FH, Chantler E, Anderson E, Nicholson R, McClelland RA, SeifMW. Ovulation induction and endometrial steroid receptors. Hum Reprod. 1994;9(12):2405-2410.

24. Ng EH, Chan CC, Tang OS, Yeung WS, Ho PC. Relationship between uterine blood flow and endometrial and subendometrial blood flows during stimulated and natural cycles. Fertil Steril. 2006;85(3):721-727.

25. Nakagawa K, Kaneyama M, Nishi Y, Sugiyama R, Motoyama H, Sugiyama R. Clomiphene citrate affects the receptivity of the uterine endometrium. Reprod Med Biol. 2014;14(2):73-78.

26. Hsu CC, Kuo HC, Wang ST, Huang KE. Interference with uterine blood flow by clomiphene citrate in women with unexplained infertility. Obstet Gynecol. 1995;86(6):917-921.
International Journal of Women's Health

\section{Publish your work in this journal}

The International Journal of Women's Health is an international, peerreviewed open-access journal publishing original research, reports, editorials, reviews and commentaries on all aspects of women's healthcare including gynecology, obstetrics, and breast cancer. The manuscript management system is completely online and includes

\section{Dovepress}

a very quick and fair peer-review system, which is all easy to use Visit http://www.dovepress.com/testimonials.php to read real quotes from published authors. 